\title{
Tubal choriocarcinoma: a rare entity
}

\author{
Shanti Sah ${ }^{1 *}$, Vaanika Kaira ${ }^{2}$ \\ ${ }^{1}$ Department of Obstetrics and Gynaecology, ${ }^{2}$ Department of Pathology, SRMS-IMS, Bareilly, Uttar Pradesh, India
}

Received: 27 August 2020

Accepted: 01 October 2020

\section{*Correspondence:}

Dr. Shanti Sah,

E-mail: shantisahmsog@gmail.com

Copyright: $\odot$ the author(s), publisher and licensee Medip Academy. This is an open-access article distributed under the terms of the Creative Commons Attribution Non-Commercial License, which permits unrestricted non-commercial use, distribution, and reproduction in any medium, provided the original work is properly cited.

\begin{abstract}
Choriocarcinoma is common after molar pregnancy and follows in almost $50 \%$ of such pregnancies, but in some rare cases it follows even after an ectopic pregnancy. Tubal choricarcinoma associated with an ectopic pregnancy has an aggressive course but it is curable.
\end{abstract}

Keywords: Tubal choriocarcinoma, Malignant tumor, Villi epithelium

\section{INTRODUCTION}

Choriocarcinoma is a highly malignant tumor arising from neoplastic changes in chorionic villi epithelium. ${ }^{1}$ Among patient with choriocarcinoma, 50\% follows molar pregnancy whereas approx $30 \%$ occurs after miscarriage or an ectopic pregnancy. ${ }^{1}$ GTN after a non molar pregnancy is always a choriocarcinoma. However, choriocarcinoma occurring after an ectopic pregnancy is very rare and tubal choriocarcinoma associated with an ectopic pregnancy has an aggressive course but still curable. $^{2}$

\section{CASE REPORT}

A 32-year-old female, $\mathrm{P}_{3} \mathrm{~L}_{3} \mathrm{E}_{1}$ presented with history of pain in abdomen since 2-3 days. She had a history of exploratory laparotomy done two and a half months back for acute left sided ruptured ectopic, following which patient did not follow up. However, during this acute episode the previous HPE report was collected which showed choriocarcinoma in the biopsied ectopic specimen. Presently, patient did not have any history of headache, seizure, syncopal attack, breathlessness, cough, epigastric pain, jaundice or vaginal discharge/bleeding. On general physical examination, mild pallor present with pulse $112 / \mathrm{min}$, BP 100/60 $\mathrm{mmHg}$. On examination, abdominal distension present along with guarding and rebound tenderness. On per-vaginum examination, fullness was present in all fornices with cervical motion tenderness. An USG was done which showed moderate free fluid with ground glass echoes in peritoneal cavity along with heterogonous ill-defined lesion in the left adenexa with increased peripheral uptake of vascularity. Keeping her previous histopathology and USG report, serum $\beta$-hCG was sent, X-ray and other relevant investigation were done which were normal. An exploratory laparotomy was planned with clinical suspicion of chorionic tissue being infiltrating into adjoining structure forming a tubo-ovarian mass with haemoperitoneum. Her initial $\beta$-hCG was $>1$ lakh $(1,17,912 \mathrm{mIU} / \mathrm{ml})$. Per operatively gross haemoperitoneum was present with left T.O. mass arising from left cornual region probably the interstitial part of tube which was distended approx. $4 \times 4 \mathrm{~cm}$ with fungating mass approx. $2 \times 2 \mathrm{~cm}$ with rent present in it with blood oozing out, while the rest tube and ovary were adhered to it (Figure 1). Per operative finding gave clinical suspicion of perforating mole. Seeing the location of the mass and patient's parity intra-operative decision of hysterectomy with left salphingo-opherectomy taken and specimen was sent for HPE. On POD 3, repeat $\beta$-hCG was done and there was markedly fall in level being $25,126 \mathrm{mIU} / \mathrm{ml}$. 
Her post operative period was uneventful and she followed on $10^{\text {th }}$ post operative day with HPE report which showed hemorrhagic and necrotic mass infilterating into the ovary and adjacent myometrium on cut section with diffuse infiltrative sheet of malignant intermediate trophoblast, cytotrophoblast and syntiotrophoblast with extensive necrosis suggestive of choriocarcinoma infiltrating adjacent ovary and myometrium (Figure 2). IHC staining showed diffuse positivity for $\beta$-hCG in the syncytiotrophoblast and cytotrophoblast. FIGO scoring was done and she was subjected to single agent multi dose chemotherapy since she was graded as stage II low risk disease without any extra-genital metastatic lesion. She responded well with fall in $\beta$-hCG level and is continued with same regime of chemotherapy and follow up with $\beta$-hCG level.

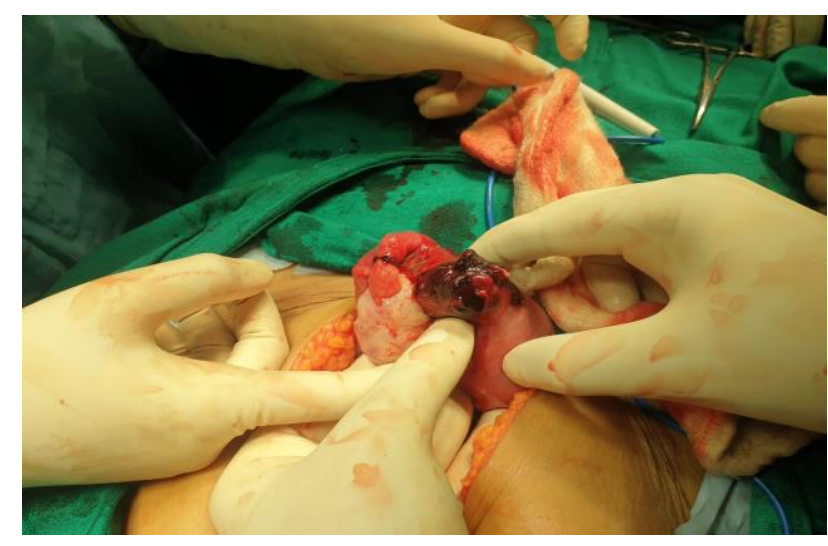

Figure 1: Intra operative picture.

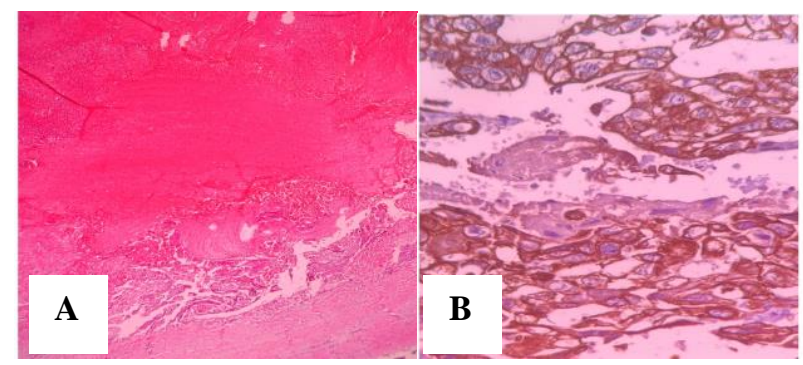

Figure 2: A) Histopathological details $(100 \mathrm{X})$, B) Histopathological details $(400 \mathrm{X})$.

\section{DISCUSSION}

Gestational trophoblastic disease comprises a variety of disorder in which choriocarcinoma is most malignant. ${ }^{3}$ Choriocarcinoma associated with ectopic pregnancy is extremely rare with and incidence of $0.76-0.40 \%$ of ectopic pregnancy but is generally very aggressive. ${ }^{4}$
Tubal choriocarcinoma can arise ether from malignant transformation of tubal pregnancy or de-novo without and ectopic pregnancy and majority present with signs and symptoms of an ectopic pregnancy. ${ }^{2}$ The typical feature of choriocarcinoma consists of column of trophoblastic cells without any villous structure with invasion of vessels and muscular tissue and extensive necrosis and hemorrhage. ${ }^{3}$ Other pathological findings include cytological atypia and numerous mitotic figure, lympho-vascular invasion with absence of chorionic villi IHC staining shows tumor positive for hCG, HSD 3B1, cytoberation A1/AE3, high Ki67, HLA-G, MUC 4 and Mel-CAM and negative stain for PLAP. ${ }^{5}$ Though choriocarcinoma has high metastatic potential, yet a highly responsive nature of tumor warrants chemotherapy even in advance cases and monitoring with $\beta$-hCG is key tool which correlate with disease volume and help guiding the therapeutic response in achieving complete cure, follow up and preventing its recurrence.

\section{CONCLUSION}

The clinical findings are quite similar to those of etopic pregnancy including amenorrhea, pelvic pain and bleeding but an initial very high level of $\beta$-hCG should provoke a clinical suspicion of such a rare entity and must have a histo-pathological verification to effectively check its aggressive nature by chemotherapy.

Funding: No funding sources Conflict of interest: None declared Ethical approval: Not required

\section{REFERENCES}

1. Kant A, Dhanesha G, Gupta U. Tubal choriocarcinoma presenting as an ectopic pregnancy. Onco Fertil J. 2019;2(2):87-9.

2. Abounouh N, Belkouchi FZ, Benyahia MA, Bargach S. Choriocarcinoma of fallopian tube: a case review. Global Jour Med Res E Gynaecology \& Obstretric. 2017;17(1):15-7.

3. Karaman E, Cetin O, Bayram I. Primary tubal choriocarcinoma presented as ruptured ectopic pregnancy. J Clin Diagn Res. 2015;9(9):QD17-8.

4. Subiman KA, Lawal I, Kolapo S, Akanbi A. Tubal choriocarcinoma in ruptured ectopic preg. Case Preport. Annals of Tropical Pathology. 2019;10(1):81-2.

5. Sonali L, Gupta R. Placenta gestational trophoblastic disease choriocarcinoma. Available at: http://www.pathologyoutlines.com/topic/placentacho riocarcinoma.html. Accessed on 20 July 2020.

Cite this article as: Sah S, Kaira V. Tubal choriocarcinoma: a rare entity. Int J Reprod Contracept Obstet Gynecol 2020;9:4747-8. 